\title{
Caracterização de genótipos de Plasmodium vivax na Ilha de São Luís, Estado do Maranhão
}

\author{
Characterization of Plasmodium vivax genotypes on the \\ Island of São Luís, State of Maranhão
}

\author{
Eloísa da Graça do Rosario Gonçalves ${ }^{1}$, Ricardo Luiz Dantas Machado², \\ Ana Rosa dos Santos ${ }^{2}$, Camila Cristina Bastos Silva Raposo ${ }^{1}$, \\ Wilma Batista de Matos ${ }^{1}$ e Antonio Rafael da Silva ${ }^{1}$
}

\begin{abstract}
RESUMO
O estudo foi desenvolvido com o objetivo de caracterizar os genótipos da proteína circunsporozoíta de Plasmodium vivax, circulantes em área periférica da Ilha de São Luís, Maranhão. Foram obtidas amostras de sangue para exame parasitológico direto (gota espessa) de 126 indivíduos, dentre os quais, foram coletadas também 109 amostras para diagnóstico molecular, por reação em cadeia da polimerase. 0 exame parasitológico demonstrou a presença de Plasmodium vivax em 2 indivíduos, sintomáticos, enquanto o estudo molecular foi positivo para o Plasmodium vivax em 7 indivíduos (2 sintomáticos e positivos na gota espessa e 5 assintomáticos e negativos na gota espessa). Em dois havia associação com Plasmodium falciparum. A genotipagem das amostras de Plasmodium vivax revelou a variante VK 210, havendo associação com a variante VK 247 em duas delas.
\end{abstract}

Palavras-chaves: Plasmodium vivax. Genótipos. Ilha de São Luís.

\begin{abstract}
This study was developed with the aim of characterizing Plasmodium vivax circumsporozoite protein genotypes on the Island of São Luís, Maranhão. Blood samples were taken for direct parasitological examination (thick blood film) from 126 individuals. Among these individuals, 109 samples were also taken for molecular diagnosis by means of the polymerase chain reaction. The parasitological examination showed the presence of Plasmodium vivax in two symptomatic individuals, while the molecular study was positive for Plasmodium vivax in seven individuals (two symptomatic and positive from the thick blood film and five asymptomatic and negative from the thick blood film). Two samples showed an association with Plasmodium falciparum. Genotyping of the Plasmodium vivax samples showed that the VK 210 variant was present. This was associated with the VK 247 variant in two samples.
\end{abstract}

Key-words: Plasmodium vivax. Genotypes. Island of São Luís.

Variações no gene da proteína circunsporozoíta (CSP) da espécie Plasmodium vivax foram reveladas por estudos realizados nas últimas décadas ${ }^{1315}$. A primeira variante seqüenciada e que se caracteriza pela presença de um nonapeptídeo repetido em tandem no domínio central da proteína, foi denominada VK210, considerada a forma clássica de Plasmodium vivax. Em cepas da Tailândia foram descritas variações no referido nonapeptídeo, sendo essa variante conhecida como VK2 $47^{15}$. Posteriormente, em Papua Nova Guiné, foi relatada a existência de uma variante denominada Plasmodium vivax-like, por ser morfologicamente semelhante ao Plasmodium vivax, mas por diferir na sequiência repetitiva da região central da CSP, bem como por induzir resposta

\footnotetext{
1. Centro de Referência em Doenças Infecciosas e Parasitárias, Departamento de Patologia, Universidade Federal do Maranhão, São Luís, MA. 2. Centro de Investigação de Microrganismos, Departamento de Doenças Dermatológicas, Infecciosas e Parasitárias, Faculdade de Medicina de São José do Rio Preto, SP.

Endereço para correspondência: Dra. Eloísa da Graça do Rosário Gonçalves. Depto de Patologia/UFMA. Praça Madre Deus, 02, Térreo, Bairro Madre Deus, 65025-560 São Luís, MA.

Tel: $55983221-0270$

e-mail: regionalsbmt@elo.com.br

Recebido para publicação em 07/08/2008

Aceito em 03/04/2009
}

imune diferente dos dois tipos anteriormente descritos ${ }^{13}$. As três variantes têm sido demonstradas em diferentes partes do mundo ${ }^{5}{ }^{7}$. No Brasil, estas variantes foram identificadas, inicialmente, por métodos sorológicos aplicados em amostras procedentes do Estado de São Paulo ${ }^{4}$ e de comunidades indígenas da região Amazônica ${ }^{3}$. Estudo empregando peptídeos sintéticos das regiões repetitivas da CSP das três variantes de Plasmodium vivax, identificou a presença de anticorpos em amostras de pacientes de uma comunidade endêmica do Estado de Rondônia ${ }^{12}$.

Estudos moleculares confirmaram a presença desses tipos variantes nos Estados de Rondônia, Amapá, Pará9 e Amazonas ${ }^{1}$, descrevendo a ocorrência do Plasmodium vivax VK210 em infecções puras, enquanto as variantes VK247 e Plasmodium vivax-like foram evidenciadas apenas em infecções mistas, tendo sido constatada correlação do genótipo encontrado do Plasmodium vivax com diferentes graus de parasitemia ${ }^{9}$, além de comportamentos clínicos e resposta terapêutica distintos ${ }^{17}$.

A transmissão desta espécie, num padrão endêmico, na Ilha de São Luís, motivou o desenvolvimento do estudo que teve por objetivo caracterizar os genótipos da proteína circunsporozoíta do Plasmodium vivax e, portanto, as variantes da espécie. Além disso, propôs-se a comparação de métodos microscópicos e 
moleculares para a caracterização de indivíduos com possível infecção assintomática.

\section{MATERIAL E MÉTODOS}

0 estudo foi desenvolvido na localidade de Guarapiranga, situada em área de preservação ambiental, no município de São José de Ribamar, a 30km de São Luís, no período de janeiro a julho de 2005. A população, constituída por 207 pessoas, exerce como atividades econômicas principais a pesca e a agricultura de subsistência, podendo ser caracterizadas como precárias as condições de vida locais ${ }^{10}{ }^{17}$. Foram incluídos todos os indivíduos que concordaram em participar, após consentimento informado. Menores de idade tiveram a autorização dos pais ou responsáveis.

0 exame parasitológico direto foi feito pelo método da gota espessa de sangue periférico, seguindo os procedimentos descritos no Manual de Diagnóstico Laboratorial da Malária do Ministério da Saúde ${ }^{11}$. As lâminas foram acondicionadas e transportadas ao laboratório do Centro de Referência em Doenças Infecciosas e Parasitárias da Universidade Federal do Maranhão (CRDIP/UFMA), onde foram coradas com Giemsa e submetidas à contagem parasitária em, pelo menos, 200 campos microscópicos, com aumento de 1.000 vezes.

Para a confirmação molecular da infecção malárica, amostras de sangue foram obtidas por punção venosa periférica, acondicionadas em tubos contendo EDTA e mantidas sob refrigeração $\left(-20^{\circ} \mathrm{C}\right)$ até o processamento no laboratório do Centro de Investigação de Microrganismos da Faculdade de Medicina de São José do Rio Preto (FAMERP).

o DNA foi extraído do sangue total utilizando o método de fenol-clorofórmio e o diagnóstico, realizado pelo protocolo de PCR aninhado, utilizando oligonucleotídeos iniciadores espécieespecíficos $^{8}$. A genotipagem da CSP do Plasmodium vivax foi realizada pelo método PCR/RFLP como descrito por Alves e $\operatorname{cols}^{2}, 2007$.

\section{RESULTADOS}

Foram incluídos 126 indivíduos dos quais foram coletadas 126 gotas espessas de sangue periférico para o estudo parasitológico direto e, dentre estes, 109 amostras de sangue para análise molecular. A distribuição por sexo e idade dos participantes é apresentada na Tabela 1. Foram diagnosticados, em exames parasitológicos diretos, dois casos de malária sintomática, caracterizada por febre elevada e calafrios: 0 primeiro, tratavase de uma criança do sexo feminino, de três anos de idade, cuja parasitemia foi 22.172 parasitas $/ \mathrm{mm}^{3}$; o segundo, paciente do sexo feminino, de 35 anos de idade, com parasitemia de 1.800 parasitas $/ \mathrm{mm}^{3}$.

Na comparação dos resultados obtidos com os dois métodos empregados, houve concordância em 104 (95,4\%) indivíduos, sendo dois positivos na gota espessa (e sintomáticos) e 102 negativos na gota espessa (e assintomáticos). Em cinco indivíduos assintomáticos, e cuja gota espessa fora negativa, a PCR apresentou positividade para Plasmodium sp (Tabela 2). A espécie Plasmodium vivax foi identificada em todas estas amostras, havendo associação com Plasmodium falciparum, em duas delas. Dentre estes cinco indivíduos, um tinha história pessoal e familiar de malária anterior; um tinha história familiar de malária prévia (nos dois casos os episódios maláricos anteriores tinham ocorrido no ano 2000); outros dois residiam na mesma casa de um dos pacientes sintomáticos e positivos na gota espessa, no momento da pesquisa. Finalmente, em relação a um paciente não havia história pessoal ou familiar de malária.

A genotipagem das amostras de Plasmodium vivax revelou a variante VK 210 em todas as amostras analisadas. Em apenas uma, havia associação com a variante VK 247. Não foi detectado Plasmodium vivax-like em nenhum indivíduo.

Os indivíduos assintomáticos, cujos exames moleculares foram positivos para Plasmodium sp foram acompanhados, prospectivamente, por um ano, não apresentando sintomas de malária, apesar de não terem recebido tratamento específico.

\section{TABELA 1}

Distribuição dos participantes do estudo por sexo e idade, Guarapiranga, Ilha de São Luis, MA, 2005.

\begin{tabular}{lccr}
\hline & \multicolumn{3}{c}{ Sexo } \\
\cline { 2 - 3 } Idade (anos) & masculino & feminino & Total \\
\hline $0-2$ & 6 & 7 & 13 \\
$3-9$ & 16 & 11 & 27 \\
$10-19$ & 16 & 9 & 25 \\
$20-29$ & 8 & 10 & 18 \\
$30-39$ & 11 & 7 & 18 \\
$40-49$ & 5 & 2 & 7 \\
$50-59$ & 3 & 4 & 7 \\
$\geq 60$ & 6 & 5 & 11 \\
\hline Total & $\mathbf{7 1}$ & $\mathbf{5 5}$ & $\mathbf{1 2 6}$ \\
\hline
\end{tabular}

TABELA 2

Métodos empregados no diagnóstico de malária, Guarapiranga, Ilha de São Luis, MA, 2005.

\begin{tabular}{|c|c|c|c|c|c|}
\hline \multirow{3}{*}{$\begin{array}{l}\text { Método } \\
\text { diagnóstico }\end{array}$} & \multicolumn{4}{|c|}{ Número de amostras } & \multirow[b]{3}{*}{ Total } \\
\hline & \multicolumn{2}{|c|}{ sintomáticos } & \multicolumn{2}{|c|}{ assintomáticos } & \\
\hline & pos & neg & pos & neg & \\
\hline Gota espessa & 2 & 0 & 0 & 124 & 126 \\
\hline PCR & 2 & 0 & 5 & 102 & 109 \\
\hline
\end{tabular}

pos: positivo, neg: negativo, PCR: reação em cadeia da polimerase

\section{DISCUSSÃO}

A malária ocorre em áreas periféricas da Ilha de São Luís, onde as condições ambientais e de vida da população favorecem a proliferação do vetor e a transmissão do agente etiológico ${ }^{10} 1417$. Com exceção de oito casos devidos ao Plasmodium falciparum, diagnosticados em 1980 na localidade de Guarapiranga ${ }^{16}$, nas últimas décadas o Plasmodium vivax tem sido responsável pela totalidade dos casos de malária nessa área, bem como em toda a 
Ilha de São Luís. No ano 2000, houve acentuação da transmissão, tendo sido relatados 63 casos. Houve 26 casos em 2001; 17, em 2002; 24, em 2003, enquanto em 2004 e 2005 foram registrados 5 e 2 casos, respectivamente. 0 acompanhamento dos pacientes mostrou a apresentação clínica clássica, sem sinais de gravidade e resposta satisfatória ao tratamento com cloroquina, associada à primaquina, numa observação que difere daquelas assinaladas em outros estudos desenvolvidos na região amazônica ${ }^{1}$.

0 estudo ora apresentado permitiu identificar os genótipos VK210 e VK247 no Estado do Maranhão, apesar do pequeno número de amostras positivas e, de acordo com outros estudos ${ }^{9}$, a variante VK 247 esteve presente em infecção mista com a VK210.

Não permitiu, no entanto, esclarecer o real significado do achado de PCR positivo para Plasmodium sp em cinco indivíduos assintomáticos e negativos no exame parasitológico de sangue periférico. Não está claro se estes indivíduos teriam papel efetivo na dinâmica de transmissão e na manutenção do padrão endêmico da malária no local, que conta com uma população pouco numerosa, estável e com pequeno movimento migratório. Neste aspecto, destaca-se o fato de quatro dos referidos indivíduos terem história pessoal ou familiar de malária, assim como convívio com pacientes maláricos no momento da pesquisa. No entanto, nenhum destes, assim como aquele que não tinha história de malária, tornou-se sintomático durante o seguimento clínico feito pelos autores por um ano.

0 encontro de marcador molecular para o Plasmodium falciparum em duas amostras gerou, igualmente, especulações. 0 achado poderia traduzir a circulação da espécie na localidade, gerando infecção assintomática? Poderia sinalizar a possibilidade do ressurgimento de casos autóctones de malária por esta espécie na Ilha de São Luís? Por outro lado, os achados reforçam a necessidade de se intensificar a atenção ao comportamento clínico, laboratorial, terapêutico e epidemiológico da doença naquela região, considerando-se que estes aspectos poderiam ser influenciados pelas variantes envolvidas na infecção ${ }^{19}$.

\section{REFERÊNCIAS}

1. Alecrim MGD. Estudo clínico e terapêutico da malária pelo Plasmodium vivax e avaliação do polimorfismo no Estado do Amazonas. Tese de Doutorado, Universidade de Brasília, Brasília, DF, 2000.

2. Alves RT, Póvoa MM, Goldman IF, Cavasini CE, Rossit ARB, Machado RLD. A new polymerase chain reaction/restriction fragment length polymorphism protocol for Plasmodium vivax circunsporozoite protein genotype (VK 210, VK247 and
P. vivax-like) determination. Diagnostic Microbiology and Infectious Disease 59: 415-419, 2007.

3. Arruda M, Souza RC, Veiga ME, Ferreira AF, Zimmerman RH. Prevalence of Plasmodium vivax variants VK247 and Plasmodium vivax-like human malaria: a retrospective study in indigeneous Indian populations of the Amazon region of Brazil. Transactions of the Royal Society of Tropical Medicine and Hygiene 92: 628, 1998.

4. Curado II, Duarte AMRC, Lal AA, Nussenzweig RS, Oliveira S, Kloetzel JK. Serological investigation of human Plasmodium vivax-like malaria in several localities in the State of São Paulo, Brazil. Memórias do Instituto Oswaldo Cruz 90: 284, 1995.

5. Gonzalez JM, Hurtado S, Arevalo-Herrera M, Herrera S. Variants of the Plasmodium vivax circumsporozoite protein (VK210 and VK247) in Colombian isolates. Memórias do Instituto Oswaldo Cruz 96: 709-712, 2001.

6. Kain KC, Keystone J, Franke ED, Lanar, DE. Global distribution of a variant of circumsporozoite gene of Plasmodium vivax. Journal of Infectious Disease 164: 208-210, 1991.

7. Kain KC, Browm AE, Lanar DE, Balllou WR, Webster HK. Response of Plasmodium vivax variants to chloroquine as determined by microscopy and quantitative polymerase chain reaction. The American Journal of Tropical Medicine and Hygiene 49: 478-484, 1993.

8. Kimura M, Kaneko 0, Zhou M, Kawamoto F, Wataya Y, Otani S, Yamaguchi Y, Tanabe K. Identification of the four species of human malaria parasites by nested PCR that targets variant sequences in the small subunit rRNA gene. Parasitology International 46: 91-95, 1997.

9. Machado RLD, Póvoa MM. Distribution of Plasmodium vivax variants (VK210, VK247 and P. vivax-like) in three endemic áreas of the Amazon region of Brazil and their correlation with chloroquine treatment. Transactions of the Royal Society of Tropical Medicine and Hygiene 94: 377-381, 2000.

10. Matos WB. Caracterização sócio-econômica e sanitária de um foco de malária em Guarapiranga, São José de Ribamar, Maranhão. Monografia. Universidade Federal do Maranhão, São Luis, 2002.

11. Ministério da Saúde. Secretaria de Vigilância em Saúde. Manual de Diagnóstico Laboratorial da Malária. Série A: Normas e Manuais Técnicos, Brasília, 2005.

12. Oliveira-Ferreira J, Pratt-Riccio LR, Santos M, Ribeiro F, Goldberg CT, Banic AC. HLA class II and antibody responses to circumsporozoite protein repeats of $P$. vivax (VK 210, VK247 and P. vivax - like) in individuals naturally exposed to malaria. Acta Tropica 92: 63-69, 2004

13. Qari SH, Shi YP, Goldman IF, Udhayarkumar V, Alpers MP, Collins WE, Lal AA. Identification of Plasmodium vivax-like human malaria parasite. Lancet 341:780-783, 1993

14. Ribeiro MCT, Gonçalves EGR, Tauil PL, Silva AR. Aspectos epidemiológicos de um foco de malária no município de São Luis, MA. Revista da Sociedade Brasileira de Medicina Tropical 38: 272-274, 2005.

15. Rosenberg R, Wirtz RA, Lanar DE, Sattabongkot J, Hall T, Waters AP, Prasittisuk C. Circumsporozoite protein heterogeneity in the human malaria parasite Plasmodium vivax. Science 245:973-976, 1989.

16. Silva AR. Malária na Ilha de São Luis, Maranhão, Brasil: determinantes de sua transmissão e importância da participação comunitária no seu controle. Tese de Doutorado. Faculdade de Medicina, Universidade Federal do Rio de Janeiro, Rio de Janeiro, RJ, 1985.

17. Silva AR, Tauil PL, Bastos Jr JL, Matos WB, Costa EAP, Gonçalves EGR. Aspectos da transmissão focal de malária na Ilha de São Luis, MA. Revista da Sociedade Brasileira de Medicina Tropical 39: 250-254, 2006. 